\section{Test Bias}

Michael Franzen

Allegheny General Hospital, Pittsburgh, PA, USA

\section{Definition}

Test bias is said to exist when the test exhibits differential validity in different populations. Test bias is sometimes confused with fairness. Test bias is a characteristic of differential validity of the test, whereas fairness is a function of the use to which the test is put and the result of decisions made on the basis of test results. If a test has differential validity in determining diagnosis in males versus females, test bias is manifest. If the same cutoff scores from that test are used to decide inpatient hospitalization for both males and females, then unfairness may be present. The issues of test fairness are often determined in the social or legal realm. Test bias is a systematic error in the measurement process. An example of how test bias can be identified in clinical neuropsychological assessment can be found in Pedraza et al. (2009).

\section{Cross-References}

Classical Test Theory

\section{References and Readings}

Berk, R. A. (Ed.). (1982). Handbook of methods for detecting test bias. Baltimore: Johns Hopkins Press.

Camilli, G., \& Shepard, L. A. (1994). Methods for identifying biased test items. Thousand Oaks: Sage Publications.

Pedraza, O., Graff-Radford, N. R., Smith, G. E., Ivnik, R. J., Willis, F. B., Petersen, R. C., et al. (2009). Differential item functioning of the Boston naming test in cognitively normal African American and Caucasian older adults. Journal of the International Neuropsychological Society, 15, 758-768. 